\title{
Spatial-Temporal Variation of Aridity Index of China during 1960-2013
}

\author{
Huiping Huang, ${ }^{1,2,3}$ Yuping Han, ${ }^{1,3}$ Mingming Cao, ${ }^{2}$ Jinxi Song, ${ }^{2}$ and Heng Xiao ${ }^{1}$ \\ ${ }^{1}$ School of Resources and Environment, North China University of Water Resources and Electric Power, Zhengzhou 450045, China \\ ${ }^{2}$ College of Urban Environmental Science, Northwest University, Xian 710127, China \\ ${ }^{3}$ Collaborative Innovation Center of Henan Province, Zhengzhou 450045, China
}

Correspondence should be addressed to Yuping Han; han0118@163.com

Received 16 March 2015; Revised 7 August 2015; Accepted 17 August 2015

Academic Editor: Mark D. Svoboda

Copyright (C) 2016 Huiping Huang et al. This is an open access article distributed under the Creative Commons Attribution License, which permits unrestricted use, distribution, and reproduction in any medium, provided the original work is properly cited.

\begin{abstract}
Aridity index, as the ration of potential evapotranspiration and precipitation, is an important indicator of regional climate. GIS technology, Morlet wavelet, Mann-Kendall test, and principal component analysis are utilized to investigate the spatial-temporal variation of aridity index and its impacting factors in China on basis of climate data from 599 stations during 1960-2013. Results show the following. (1) Boundaries between humid and semihumid region, and semihumid and semiarid region coincide with $400 \mathrm{~mm}$ and $800 \mathrm{~mm}$ precipitation contour lines. (2) Average annual aridity index is between 3.4 and 7.5 and shows decrease trend with a tendency of -0.236 per decade at $99 \%$ confidence level. (3) The driest and wettest month appear in December and July, respectively, in one year. (4) Periods of longitudinal and latitudinal shift of aridity index 1, 1.5, and 4 contours coordinate are 10 and 25 years, 6 and 26 years, and 5 and 25 years, respectively. (5) Four principal components which affect aridity index are thermodynamic factors, water and radiation factors, geographical and air dynamic factors, and evaluation factor, respectively.
\end{abstract}

\section{Introduction}

Aridity index is the ratio of annual potential evapotranspiration $\left(\mathrm{ET}_{0}\right)$ and annual precipitation (UNESCO [1], FAO [2], and UNEP [3]) and it usually reflects the degree of climatic drought. Regions where aridity index is less than 1.0 are classified as wet areas (Ponce et al. [4]); the regions where aridity index is more than 1 are classified as dry areas since the evaporative demand cannot be met by precipitation. China is classified as humid area, semihumid area, semiarid area, and arid area mainly based on aridity index assisted by precipitation. Humid area is the region where aridity index is less than 1 , semihumid area is the region where aridity index is between 1.5 and 1 , semiarid area is the region where aridity index is between 1.5 and 4 , and arid area is the region where aridity index is more than 4 (Zheng et al. [5], Zheng et al. [6]). $\mathrm{ET}_{0}$ refers to the largest amount of evaporation that will occur if the sufficient water surface is available and it is a function of temperature, vapor pressure, wind speed, humidity, and solar radiation (Penman [7]). So the spatial-temporal variation of aridity index change is the reflection on change of all climatic factors.

Effect of climate changes on hydrological regimes, especially hydrological extremes, for example, droughts and floods, has become a priority area both for process research and for water management practices (Zhang et al. [8]). Many researchers have reported impacts of changes in climatic variables, such as precipitation, air temperature, sunshine hour, and wind speed, on the world. In China, $400 \mathrm{~mm}$ and $800 \mathrm{~mm}$ rainfall contours had a shifting trend toward west and south during 1960-2010 (Yuan et al. [9]). Aridity index in northwest China indicated that the region became wetter from 1960 to 2010 (Liu et al. [10]). Investigation shows that aridity index in Turkey during 1930 to 2000 increased at many stations (Türkeş [11]). There is decrease in aridity index in Iran and decrease was more obvious in the semiarid region than in the humid region (Tabari and Aghajanloo [12]). During 1960-2005, eastern Greece has shifted from the "humid" class towards the "subhumid" and "semiarid" classes and at the end of the twenty-first century drier conditions are 
expected to appear in Greece (Nastos et al. [13]). Based on collected meteorological data, we present a detailed analysis of spatial-temporal variations and its impacting factors in aridity index in China.

\section{Data and Methodology}

2.1. Data. Daily and yearly precipitation, maximum, minimum, and mean air temperature, wind speed (at $10 \mathrm{~m}$ aboveground surface), humidity, vapor pressure, and sunshine hour covering from 1960 to 2013 were collected from 599 meteorological stations from the China Meteorological Administration (CMA) and National Meteorological Information Center of China (NMIC). The data was released as the data set (SURF_CLI_CHN_MUL_DAY) after quality control in the Web site http://data.cma.gov.cn/. Missing data were estimated by the average value of the other years observed at the same station (missing data are mainly concentrated in 1967, 1968, and 1969) (Huang et al. [14]). There exist 10 first-level river basins in China and they are, namely, Songhua River Basin (SRB), Liao River Basin (LRB), Hai River Basin (HaRB), Yellow River Basin (YeRB), Huai River Basin (HuRB), Yangtze River Basin (YaRB), Southeast Rivers Basin (SERB), Pearl River Basin (PRB), Southwest Rivers Basin (SWRB), and Northwest Rivers Basin (NWRB). The DEM data of China is from Computer Network Information Center, Chinese Academy of Sciences. The location of the meteorological stations and 10 river basins is shown in Figure 1.

\subsection{Methodology}

2.2.1. Potential Evaporation $\left(E T_{0}\right)$. According to definition of aridity index of UNEP (1992), calculation of aridity index needs reference evapotranspiration $\left(\mathrm{ET}_{0}\right)$ and precipitation data. $\mathrm{ET}_{0}$ is estimated using the Penman-Monteith (PM) equation (Allen et al. [15]) which is the standard equation for $\mathrm{ET}_{0}$. The formula is given as

$$
\begin{aligned}
& \mathrm{ET}_{0} \\
& =\frac{0.408 \Delta\left(R_{n}-G\right)+\gamma(900 /(T+273)) U_{2}\left(e_{s}-e_{a}\right)}{\Delta+\gamma\left(1+0.34 U_{2}\right)},
\end{aligned}
$$

where $\mathrm{ET}_{0}$ is daily potential evapotranspiration $\left(\mathrm{mm} \cdot \mathrm{d}^{-1}\right)$; yearly and monthly $\mathrm{ET}_{0}$ data are used in this paper; $R_{n}$ is the net radiation at the top surface $\left(\mathrm{MJ} \cdot \mathrm{m}^{-2} \cdot \mathrm{d}^{-1}\right) ; G$ is the soil heat flux density $\left(\mathrm{MJ} \cdot \mathrm{m}^{-2} \cdot \mathrm{d}^{-1}\right) ; T$ is mean daily air temperature at $2 \mathrm{~m}$ height $\left({ }^{\circ} \mathrm{C}\right) ; U_{2}$ is daily average wind speed at $2 \mathrm{~m}$ height $\left(\mathrm{m} \cdot \mathrm{s}^{-1}\right) ; e_{s}$ is saturation vapor pressure $(\mathrm{kPa}) ; e_{a}$ is actual vapor pressure $(\mathrm{kPa}) ; \Delta$ is slope of $e$ vapor pressure curve $\left(\mathrm{kPa} \cdot{ }^{\circ} \mathrm{C}^{-1}\right) ; \gamma$ is the psychrometric constant $\left(\mathrm{kPa} \cdot{ }^{\circ} \mathrm{C}^{-1}\right)$.

2.2.2. Calculation of Aridity Index. Aridity index $(\phi)$ is the ratio of potential evapotranspiration and precipitation which can be expressed as

$$
\phi=\frac{\mathrm{ET}_{0}}{P}
$$

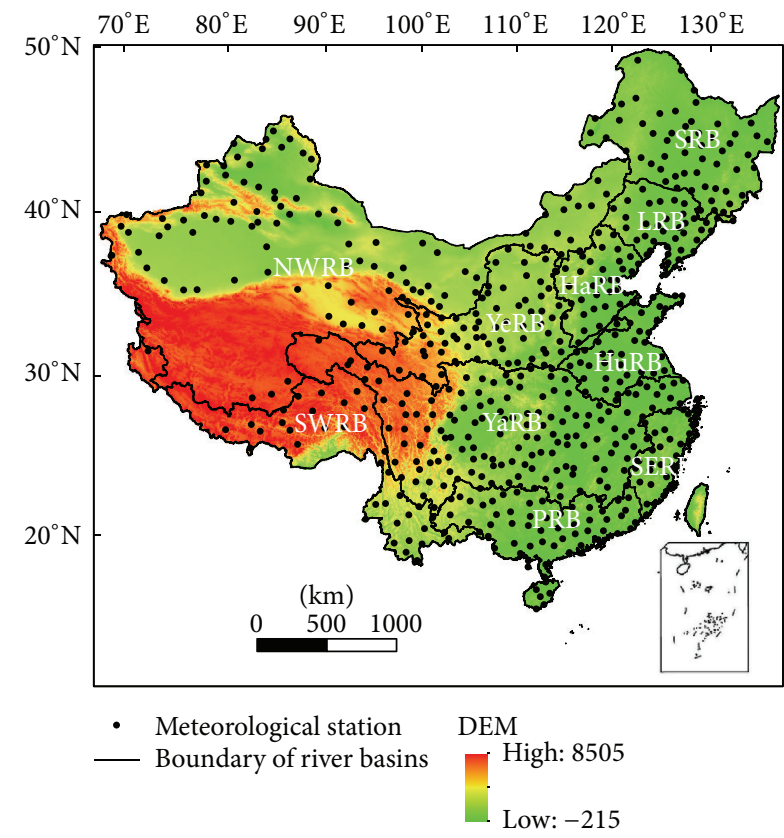

FIGURE 1: Spatial distribution of meteorological stations in China.

where $\mathrm{ET}_{0}$ is the potential evapotranspiration $(\mathrm{mm})$ and $P$ is the precipitation $(\mathrm{mm})$ in statistical period.

2.2.3. Interpolation of $E T_{0}$ and Precipitation. This paper uses collaborative Craig interpolation method (COK) to transfer yearly meteorological data of each station into $10 \mathrm{~km} \times$ $10 \mathrm{~km}$ grid map. COK changes the best estimating method of regional variables from one single attribute to 2 or more than 2 attributes. One of the attributes is main and others are auxiliary. COK combines self-correlation of main attribute and interaction of main and auxiliary attributes into unbiased optimal estimation. It is applicable for multiple regional variables which related to each other; it can estimate the required variables with one or more secondary variables and has been widely used (Hevesi et al. [16], Hevesi et al. [17]). Based on Cokriging tool embedded in geostatistical analysis module in ArcGIS software, precipitation and $\mathrm{ET}_{0}$ are interpolated in this paper.

2.2.4. Mean Center of Aridity Index Contour Line. The aridity index contour lines of $1,1.5$, and 4 in every year during 1960 to 2013 are extracted from the aridity index grid map. In order to get the average location of each contour line, this paper adopts weighted average of aridity index contour line to characterize its spatial position. The spatial changes in aridity index line can be characterized on the extracted center coordinates of each contour line in every year (Wang et al. [18]). The weighted average location of aridity index contour can be obtained using Mean Center tools in ArcGIS which located in the Spatial Statistical Tools.

2.2.5. Spatial and Temporal Trend Analysis. The simple linear regression method was used to estimate the trend magnitudes (slope) in aridity index and other climatic variables including 


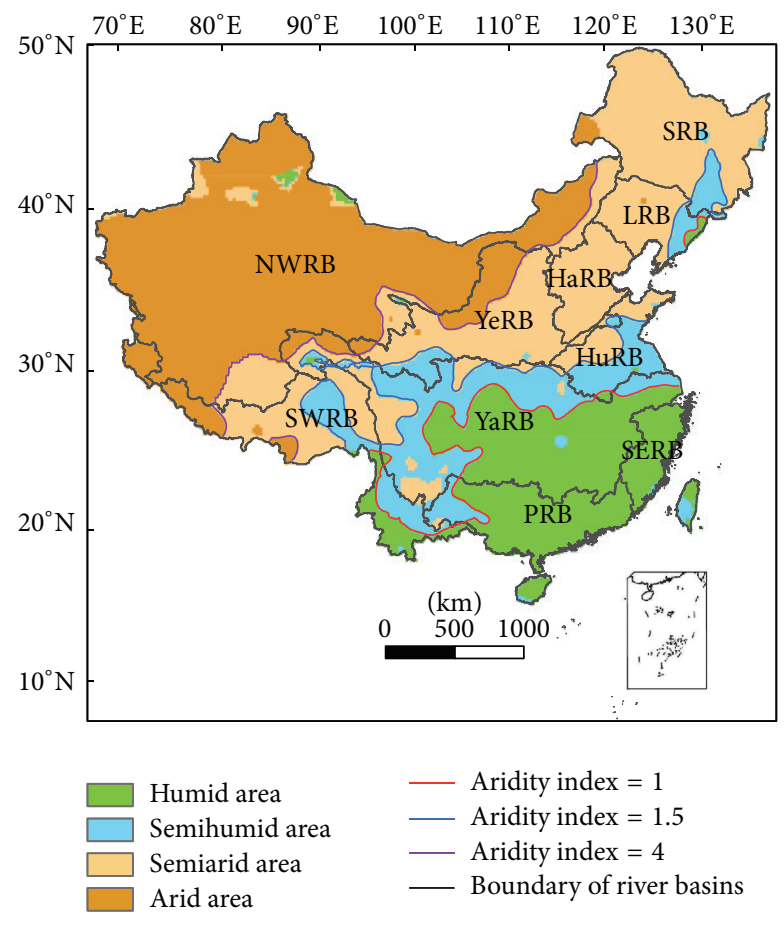

FIGURE 2: Distribution of average annual aridity index in China.

air temperature $\left({ }^{\circ} \mathrm{C}\right)$, relative humidity $(\%), 2 \mathrm{~m}$ wind speed $\left(\mathrm{m} \mathrm{s}^{-1}\right)$, and sunshine hours (h) used in P-M method (Xing et al. [19]). Meanwhile we apply the Mann-Kendall (MK) method (Mann [20], Kendall [21]) which is distributionfree, is robust against outliers, and has a higher power than many other commonly used tests (Dinpashoh et al. [22]) to recognize the temporal trend of aridity index. This paper decomposed the shift of weighted average position of aridity index contour line into longitudinal and latitudinal shift, and analysis of the periodic shift used Morlet wavelet.

\section{Results}

\subsection{Spatial Change of Multiyear Average Aridity Index}

3.1.1. Annual Distribution of Aridity Index. China is divided into 4 types of regions based on average aridity index (Zhang et al. [8]). Figure 2 shows the spatial distribution of different regions. Arid region is located in mainly NWRB, a little part of northwest in YeRB and northwest of SWRB. The semiarid region includes most part of SRB, LRB, YeRB, and SWRB, whole part of $\mathrm{HaRB}$ and half of HuRB in the north part. Semihumid region consists of east SRB, LRB, south of HuRB, north of YaRB, east of SWRB, and west of PRB. Humid region includes most of YaRB, PRB, and all of SERB. Boundary between arid area and semiarid area basically coincided with the $400 \mathrm{~mm}$ contour of precipitation; boundary between semihumid area and humid area basically coincided with the $800 \mathrm{~mm}$ contour of precipitation (Fu et al. [23]). There exist enclaves in every kind of region such as two parts of humid regions located in the arid area in NWRB. The reason humid claves locate arid area in NWRB is that in Tianshan mountain area precipitation is more than other regions for its terrain. The reason other enclaves exist is because of the different aridity index associated with the terrain there.

3.1.2. Seasonal Distribution of Aridity Index. Aridity index shows different distribution pattern in spring, summer, autumn, and winter (Table 1 and Figure 3). Summer is the wettest season and winter is the driest in one year. In winter, only SERB belongs to the humid area; HaRB, HuRB, YeRB, NWRB, and SWRB belong to arid area. In summer, YaRB, SERB, SRB, SWRB, and PRB all belong to humid area. Autumn is relatively wetter than spring and no season is humid in HaRB, HuRB, YeRB, LRB, and NWRB.

It can be seen from Figure 3 that scope of arid region is the minimum in summer and maximum in winter. Arid only exists in most part of NWRB and a little part of SWRB in summer and exists in most part of all China including all of YeRB, HaRB, most part of NWRB, SWRB, and LRB, and west part of PRB, YaRB, and SRB. Area of arid in autumn is basically the same with that of the whole year. Semiarid area is different in autumn and winter from other times. Semihumid region is the smallest and the region is like a stripe among semiarid region and humid region in spring and winter. Humid region is different in autumn compared with the other seasons; it only locates in the middle part of YaRB and a little southeast part of SWRB.

Among aridity index calculation in seasonal scale, there exists condition that there is no precipitation in some stations. When precipitation is 0 in one station in one statistical time, we adopt the maximum aridity index in the same station in the same season in 1960-2013. Precipitation is 0 which indicates the extreme drought in one region. In spring, precipitation is 0 in 9 stations in 1968, 7 stations in 1963 and 1994. In Lenghu station, which locates in NWRB, precipitation is 0 during 17 years. There are 29 stations which exist in one or more years when precipitation is 0 . Among the 29 stations 26 stations are located in NWRB. In summer, in Bachu station which locates in NWRB, there are 12 years when precipitation is 0 . In autumn, stations where there is no precipitation peak are 18 in 1991 . There are 35 stations which exist in one or more years when there is no precipitation; the no-precipitation years are more than 10 in 9 stations which all belong to NWRB. In winter, which is the driest season in China, it is only in 1995 that all stations have precipitation. There are 116 stations which exist in one or more years when there is no precipitation and the no-precipitation years are more than 10 years in 20 stations.

\subsection{Temporal Change of Aridity Index}

3.2.1. Change of Annual Aridity Index in China. Figure 4(a) shows the spatial distribution of aridity index change trends for 599 meteorological stations from 1960 to 2013 in China. There are 309 stations present increasing trend and they are mainly located in the middle part of China, including west of SRB, most of HaRB and YeRB, west of YaRB and PRB, and east of SWRB. In NWRB, aridity index in 10 stations increases and aridity index of other 133 stations decreases. Particularly, 39 stations show significant decrease (95\% confidence level), 
TABLE 1: Seasonal aridity index in different river basins.

\begin{tabular}{lcccccccccc}
\hline & YaRB & SERB & HaRB & SRB & HuRB & YeRB & LRB & NWRB & SWRB & PRB \\
\hline Annual & 0.922 & 0.723 & 2.107 & 1.316 & 2.135 & 1.689 & 1.738 & 7.021 & 1.238 & 0.776 \\
Spring & 0.96 & 0.518 & 5.221 & 2.111 & 3.49 & 3.756 & 3.843 & 10.948 & 2.188 & 0.736 \\
Summer & 0.788 & 0.756 & 1.229 & 0.901 & 1.607 & 1.012 & 1.182 & 5.894 & 0.693 & 0.568 \\
Autumn & 0.988 & 1.068 & 2.411 & 1.408 & 1.61 & 2.029 & 1.944 & 7.009 & 1.184 & 0.989 \\
Winter & 1.363 & 0.719 & 7.752 & 2.26 & 6.574 & 4.39 & 2.349 & 4.826 & 4.65 & 1.654 \\
\hline
\end{tabular}

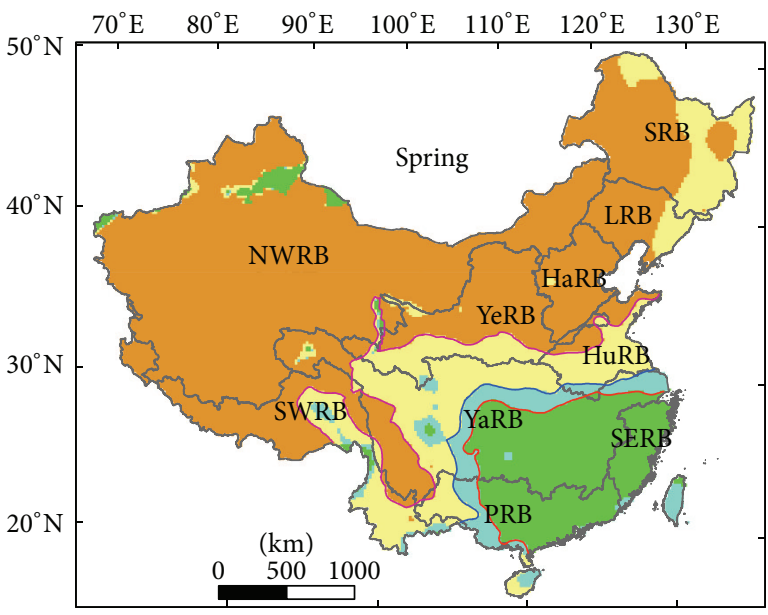

(a)

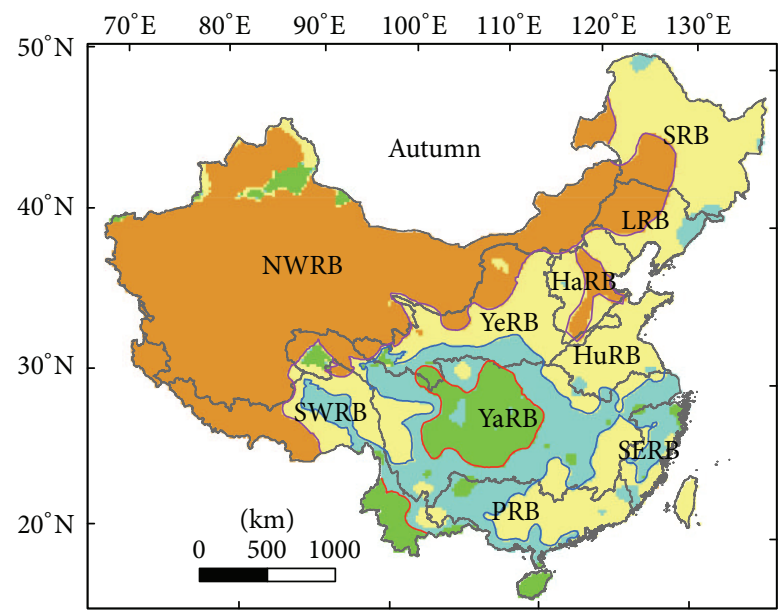

(c)

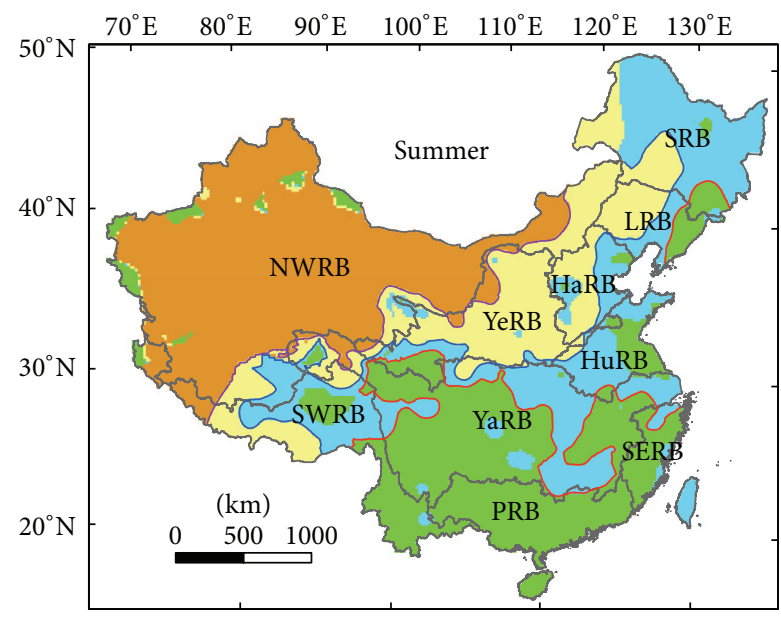

(b)

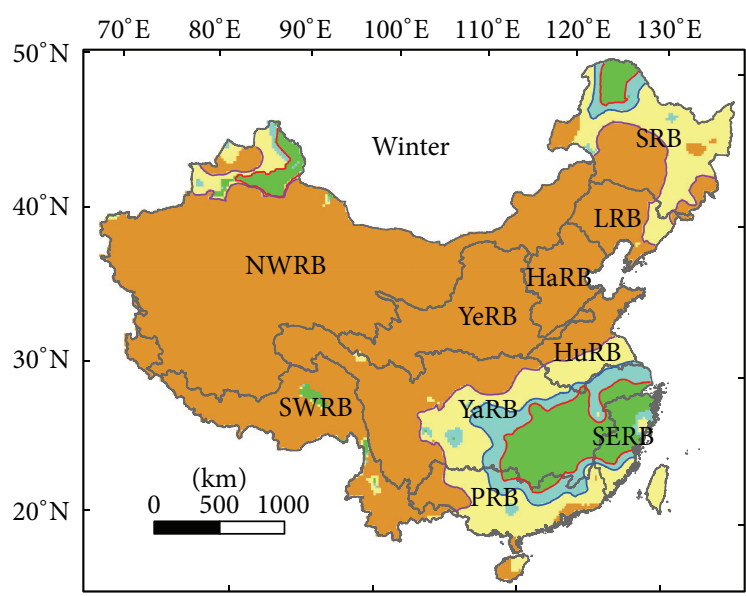

(d)

FIgURE 3: Distribution of seasonal aridity index in China. (The legend is the same as Figure 2.)

accounting for $69.6 \%$ of all the significant decrease in China. In SERB, 20 stations show decrease which account for $71.4 \%$ of the region.

Figure 4(b) indicates change of annual aridity index averaged by weight of Thiessen polygon of 599 stations in 1960-2013. Average of aridity index is between 3.4 and 7.5; the driest year appears in 1980 and the wettest year appears in 2003. Annual aridity index shows decrease trend with a tendency of -0.236 per decade at $99 \%$ confidence level which indicates that China became wetter during 1960-2013.
3.2.2. Change of Monthly Aridity Index. Aridity index has the obvious monthly characteristics and Figure 5 shows the variation of it in 10 river basins in whole China. In NWRB, HaRB, HuRB, LRB, NWRB, SRB, and whole China, July is the wettest month, in PRB, SERB, and YaRB, June is the wettest month, and in YeRB September is the wettest month. The driest month dispersed in January, March, April, October, and December. In all the monthly statistical data, maximum data 11.62 appears in NWRB in April and minimum data 0.44 appears in SERB in June. The wettest region is SERB and there 


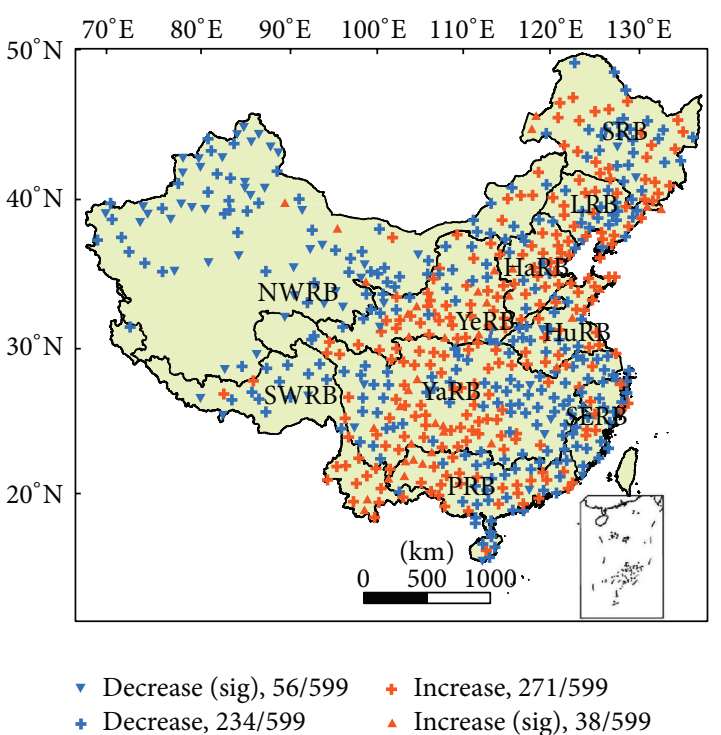

(a)

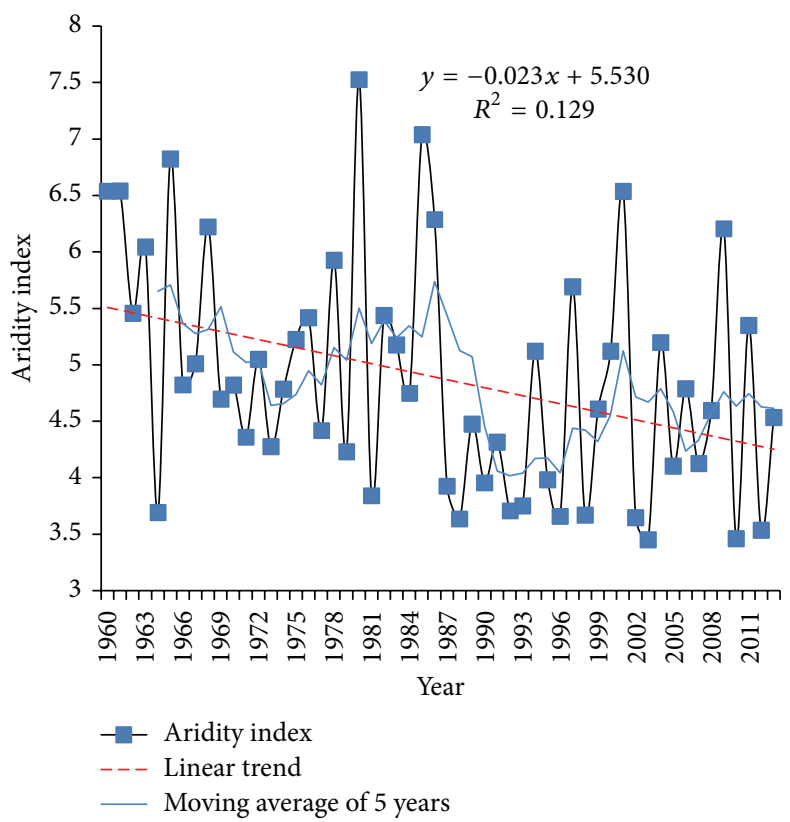

(b)

FIgURE 4: Change of annual aridity index.

are eight months in which aridity index is less than 1 but in YeRB and NWRB data in all months are more than 1. In China as a whole, aridity index is between 0.95 and 2.3, and maximum value appears in December.

\subsubsection{Space Change Trend of Interannual Aridity Index Con-} tour Line. In China, average coordinate for aridity index contour lines of $1,1.5$, and 4 is (115.1, 35.24), (113.35, 37.91), and $(95.87,32.74)$, and the points locate in northeast of HuRB, middle of HaRB, and north of SWRB, respectively. Figure 6 shows coordinate for aridity index contour lines of $1,1.5$, and 4 during 1960-2013. In 1960-2013, point of aridity index contour line moves towards to south and west. Slope of contour 1 is -0.057 and -0.081 , slope of contour 1.5 is $-0.107,-0.062$, and slope of contour 4 is $-0.017,-0.032$ in longitudinal and latitudinal direction, respectively. Shift of aridity index 1.5 in longitudinal direction is significant; other shifts of the mean center coordinate vibrate so the trend is not significant. All the shifts indicate that the climate is changing towards wet in China in 1960-2013.

\subsubsection{Periodic Analysis of Interannual Aridity Index Contour} Line. Figure 7 is modular square map of Morlet wavelet transform coefficients for mean center coordinates of different aridity index contour lines. Red lines indicate positive phase and comparative big data period; blue lines indicate negative phase and comparative small data period. Figures clearly reflect fluctuation of mean center coordinates of different aridity index contour lines. There exist different periodic changes in mean center for longitude and latitude coordinate. 10 and 25 years' periods exist in shift of aridity index 1 contour coordinate in both longitudinal and latitudinal direction, of which 10 years is the main cycle. 6 and 26 years' cycles exist in shift of aridity index 1.5 contour coordinate in both longitudinal and latitudinal direction and 5 years is the main cycle. 5 and 25 years' cycles exist in shift of aridity index 4 contour coordinate in both longitudinal and latitudinal direction and 5 years is the main cycle.

\subsection{Interaction between Changes in Aridity Index and Climate Variables}

3.3.1. Change in Climate Variables. Table 2 shows slope of climate variables averaged by meteorological stations in each river basin from 1960 to 2013. Except for $T_{\max }$ in HuRB, all temperature variables show increase trend significantly, of which increase in $T_{\min }$ is the biggest and increase of $T_{\text {min }}$ in NWRB reached $0.486^{\circ} \mathrm{C}$ per decade. Humidity in all regions shows decrease trend and decrease in 7 basins is significant, but the descendent is less in LRB, NWRB, SWRB, and YeRB. Change trend in vapor pressure is significant in SRB, HuRB, LRB, and NWRB with slope being 0.077, 0.187, 0.074 , and 0.049 , respectively. However, trend in SERB and PRB is decrease. Significant decrease is detected in wind speed change and slope in SRB is the biggest. Except increase in SWRB, sunshine hour is decreasing significantly in other river basins. Precipitation change is different and there is no consistent trend in 10 river basins. Except in NWRB, change of precipitation is insignificant.

3.3.2. Principal Component Analysis of Aridity Index. There are many methods to quantify the contributions of climate variables change in aridity index, because meteorological variables impacted each other and they are not totally 

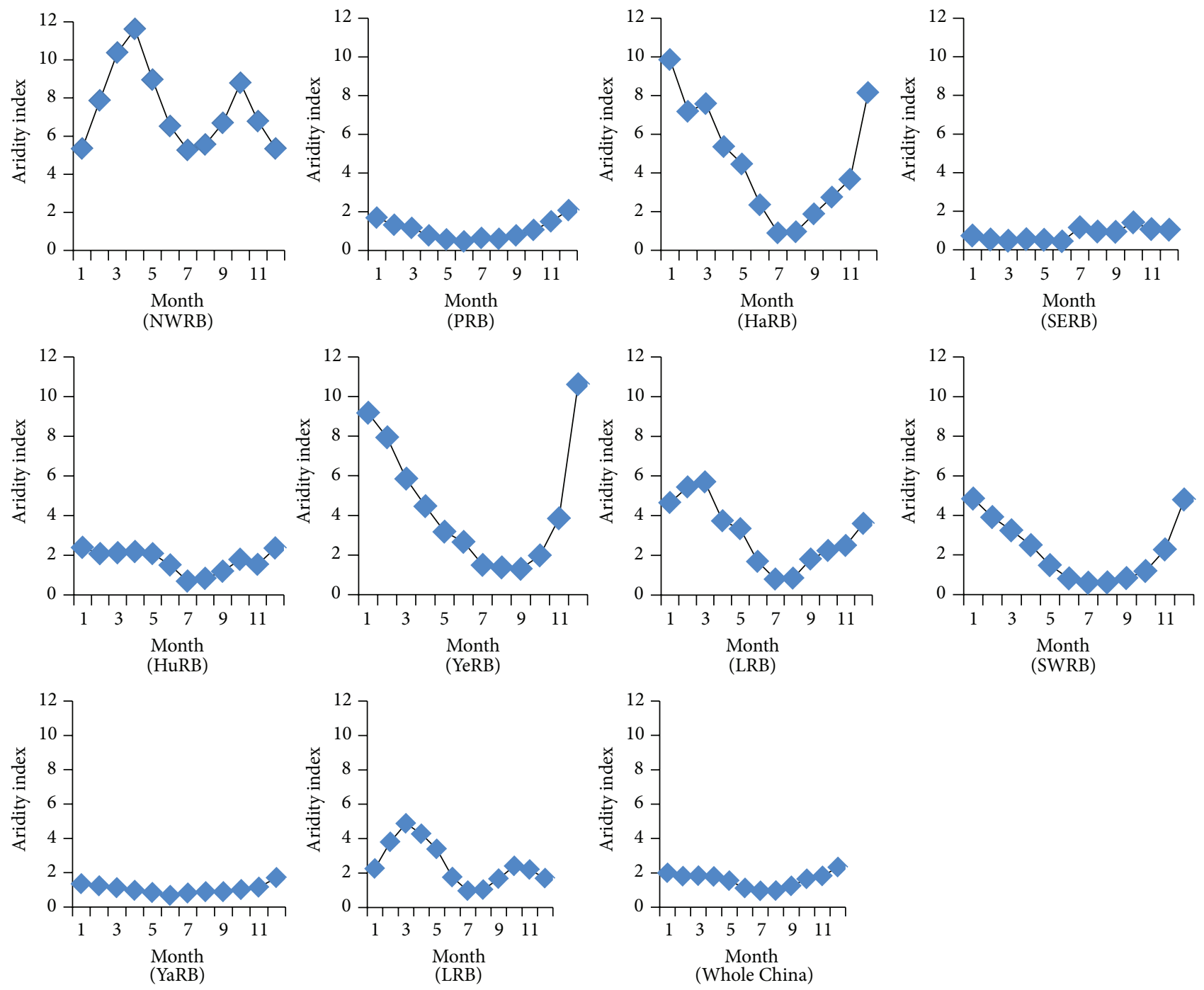

Figure 5: Monthly distribution of aridity index in different river basin.

TABLE 2: Variations of various climate variables averaged from 1960 to 2013.

\begin{tabular}{lcccccccccc}
\hline & YaRB & SERB & HaRB & SRB & HuRB & YeRB & LRB & NWRB & SWRB & PRB \\
\hline$T_{\text {max }}\left({ }^{\circ} \mathrm{C}\right)$ & $0.226^{* *}$ & $0.258^{* *}$ & $0.273^{* *}$ & $0.275^{* *}$ & 0.111 & $0.353^{* *}$ & $0.231^{* *}$ & $0.345^{* *}$ & $0.333^{* *}$ & $0.125^{*}$ \\
$T_{\text {mean }}\left({ }^{\circ} \mathrm{C}\right)$ & $0.18^{* *}$ & $0.214^{* *}$ & $0.285^{* *}$ & $0.337^{* *}$ & $0.202^{* *}$ & $0.277^{* *}$ & $0.238^{* *}$ & $0.343^{* *}$ & $0.282^{* *}$ & $0.14^{* *}$ \\
$T_{\min }\left({ }^{\circ} \mathrm{C}\right)$ & $0.238^{* *}$ & $0.243^{* *}$ & $0.41^{* *}$ & $0.485^{* *}$ & $0.246^{* *}$ & $0.331^{* *}$ & $0.343^{* *}$ & $0.486^{* *}$ & $0.358^{* *}$ & $0.199^{* *}$ \\
Humidity (\%) & $-0.536^{* *}$ & $-0.836^{* *}$ & $-0.6^{* *}$ & $-0.465^{* *}$ & $-0.877^{* *}$ & $-0.511^{*}$ & -0.117 & -0.133 & -0.34 & $-0.637^{* *}$ \\
Vapor pressure (kPa) & 0.003 & -0.029 & 0.055 & $0.077^{*}$ & $0.187^{* *}$ & 0.027 & $0.076^{* *}$ & $0.074^{* *}$ & $0.049^{*}$ & -0.034 \\
Wind speed (m·s $\left.{ }^{-1}\right)$ & $-0.087^{* *}$ & $-0.132^{* *}$ & $-0.163^{* *}$ & $-0.189^{* *}$ & $-0.108^{* *}$ & $-0.075^{* *}$ & $-0.185^{* *}$ & $-0.152^{* *}$ & $-0.053^{* *}$ & $-0.044^{* *}$ \\
Sunshine hour (h) & $-0.112^{* *}$ & $-0.164^{* *}$ & $-0.233^{* *}$ & $-0.095^{* *}$ & $-0.185^{* *}$ & $-0.084^{* *}$ & $-0.185^{* *}$ & $-0.043^{* *}$ & 0.009 & $-0.133^{* *}$ \\
Precipitation $(\mathrm{mm})$ & -2.813 & 20.316 & -13.107 & 0.679 & -8.647 & -8.508 & -4.768 & $6.018^{* *}$ & 3.049 & 4.445 \\
\hline
\end{tabular}

${ }^{* *} 99 \%$ confidence level; ${ }^{*} 95 \%$ confidence level; the slope is the value of aridity index per decade.

independent. For example, increase in precipitation may lead to an increase in humidity but decrease in air temperature. In addition, partial derivatives of aridity index to climate variables are not constant but fluctuated in statistical period. This paper adopts principal component analysis to discuss main factors impacting aridity index and operation is completed in SPSS. The adopted influencing factors in this paper include 11 variables which include climate variables listed in Table 2 and longitude, latitude, and evaluation. Evaluation of every metrological station is extracted from DEM data of China. 


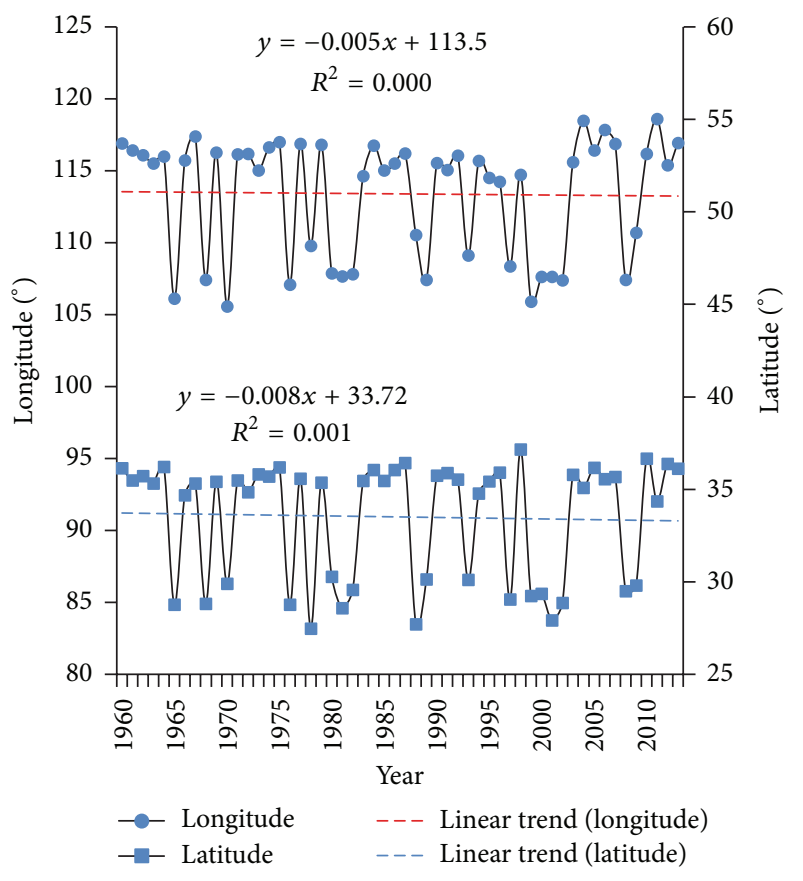

(a) Aridity index $=1$

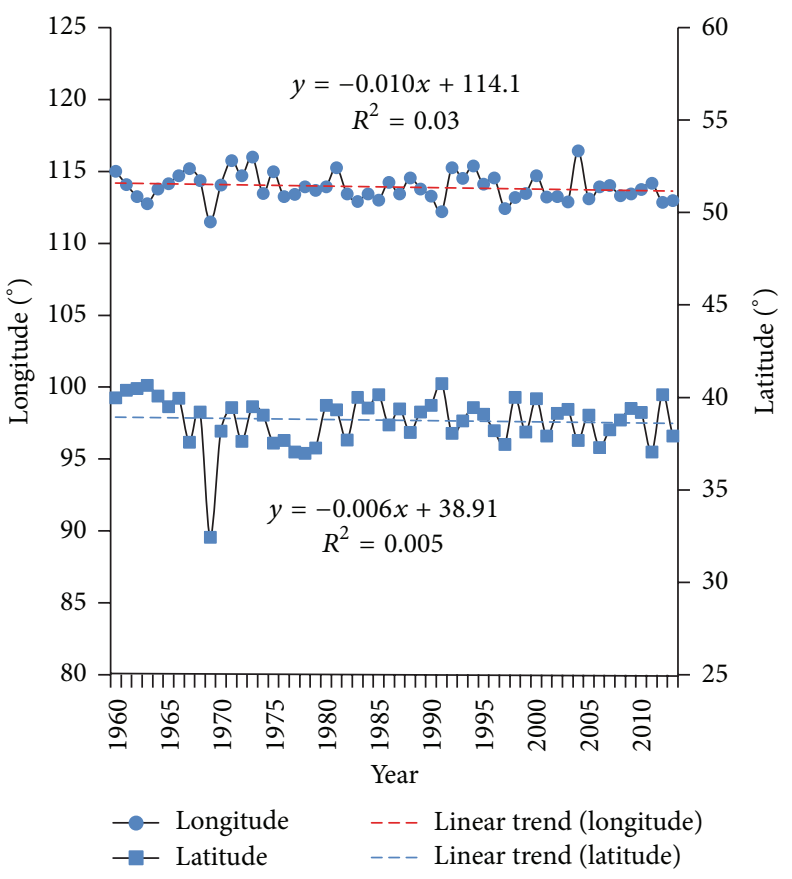

(b) Aridity index $=1.5$

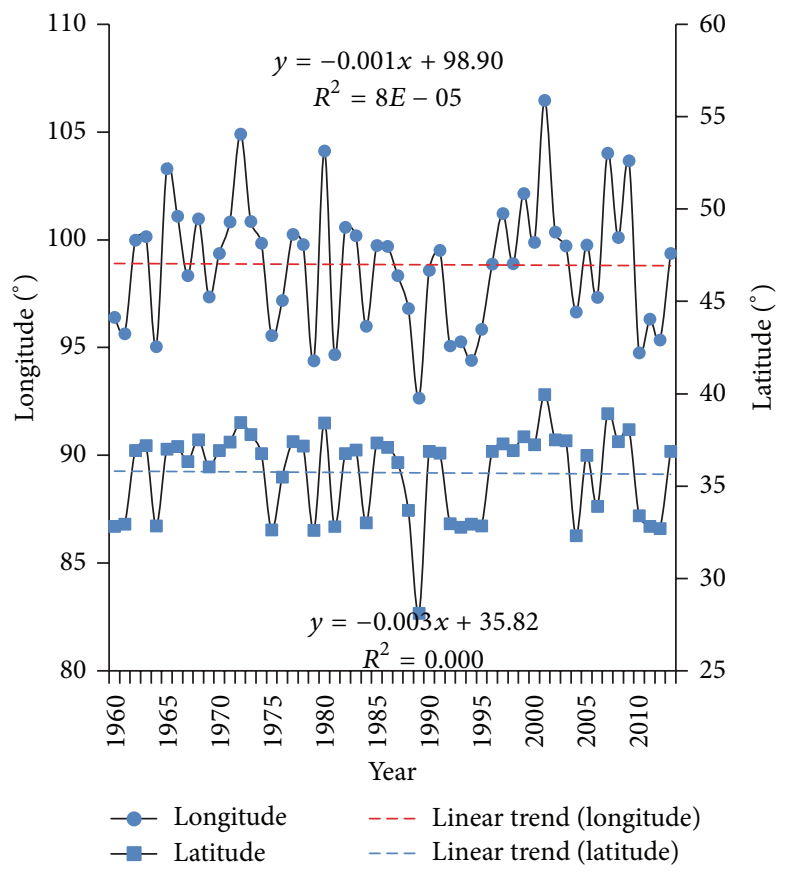

(c) Aridity index $=4$

FIgURE 6: Annual spatial shift of mean center of different aridity index contour line.

Table 3 is total variance decomposition for each factor; it can be seen that characteristics of the first 4 principal components account for $90.62 \%$ of the total variance. That is, the first 4 principal components have covered most information of the 11 factors. So the first 4 principal components are selected to substitute for the 11 factors and the first principal carries $58.77 \%$ information of the total factors.
Although the first 4 principal components have summarized $90.62 \%$ information of all the influencing factors, there is little difference in the coefficients of each primitive variable. Variance maximization rotation is adopted on the loading matrix in this paper in order to explain the factor better and Table 4 is the rotated component matrix. It can be seen from Table 4 that the first principal component 


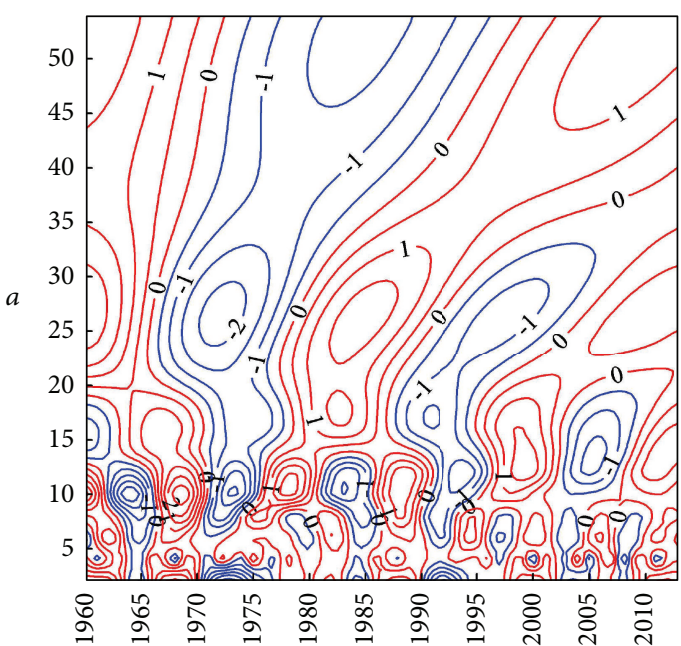

(a) Aridity index $=1$ (longitude)

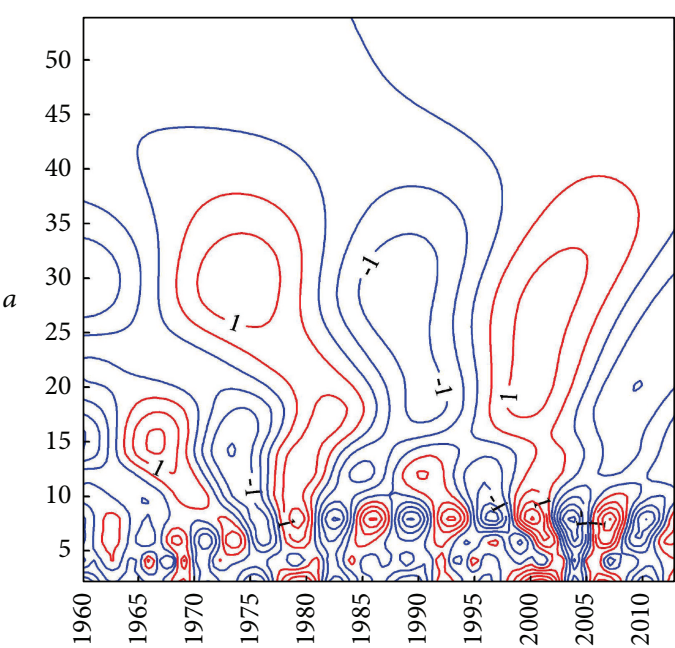

(c) Aridity index $=1.5$ (longitude)

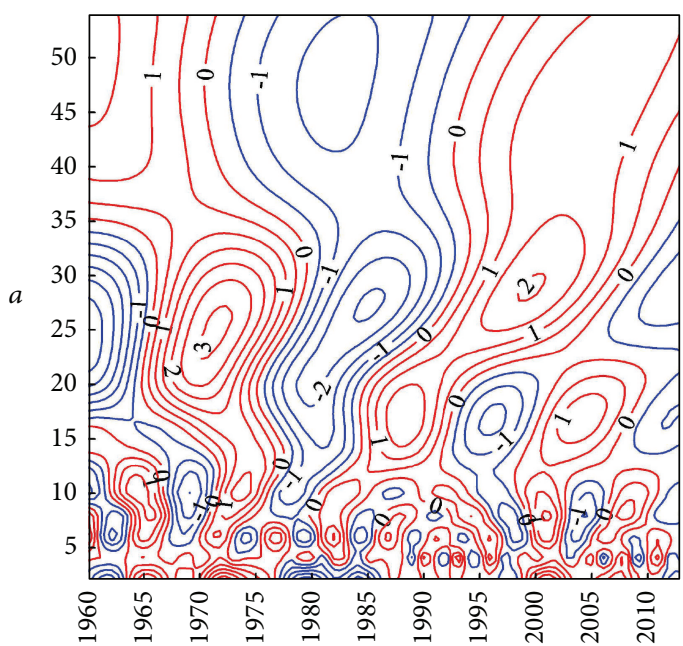

(e) Aridity index $=4$ (longitude)

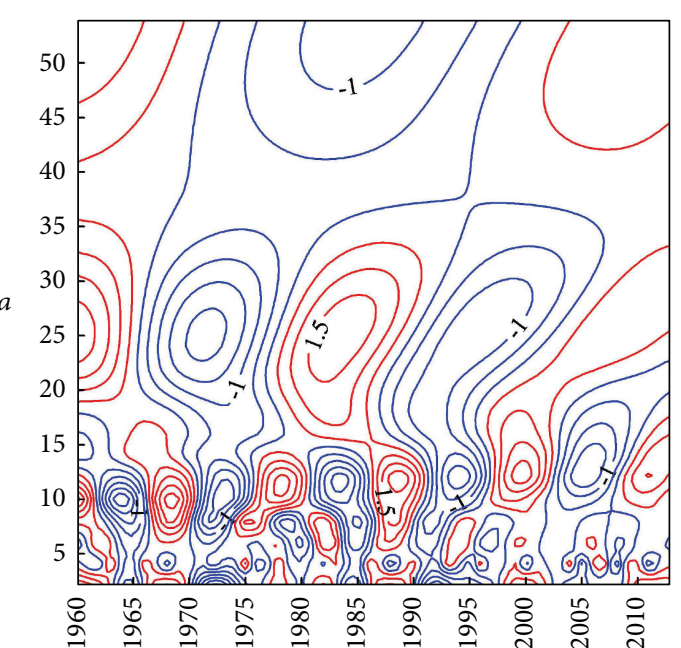

(b) Aridity index $=1$ (latitude)

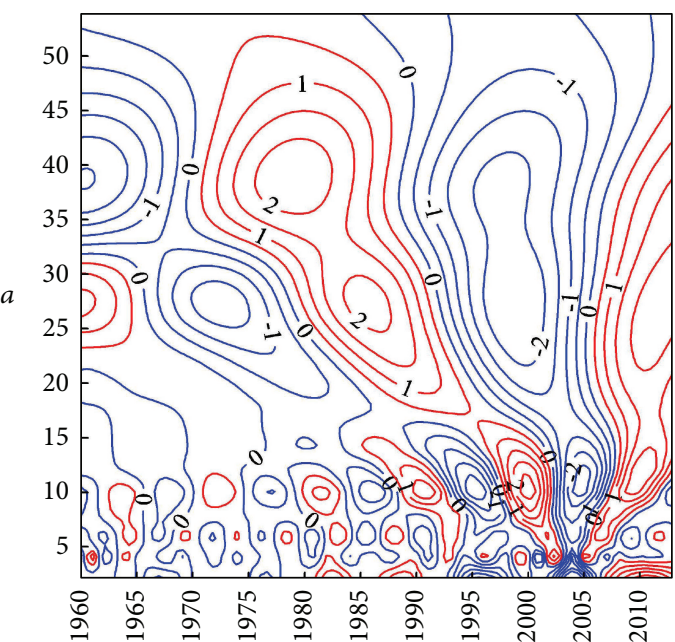

(d) Aridity index $=1.5$ (latitude)

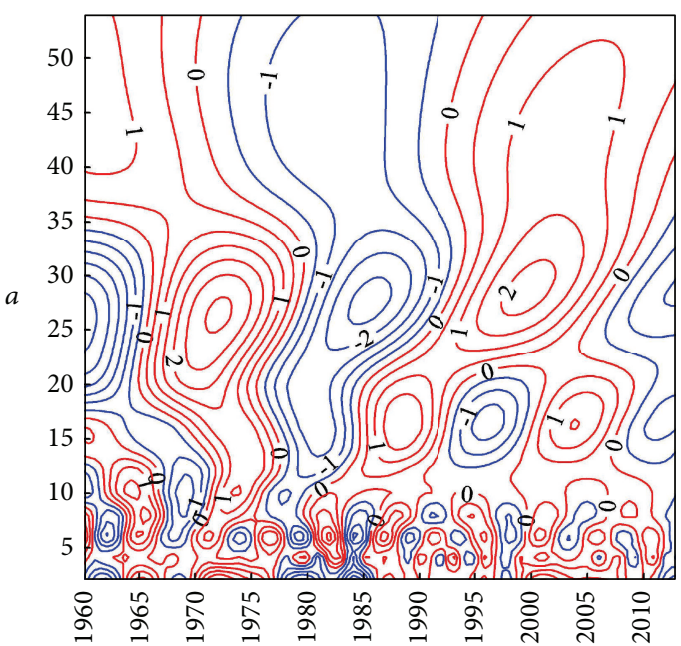

(f) Aridity index $=4$ (latitude)

FIGURE 7: Wavelet variance diagrams of the mean centers. 
TABLE 3: Eigenvalues and squared loadings of the principal components.

\begin{tabular}{lcccccccccccc}
\hline & 1 & 2 & 3 & 4 & 5 & 6 & 7 & 8 & 9 & 10 & 11 \\
\hline Eigenvalues & 6.46 & 1.71 & 0.97 & 0.83 & 0.37 & 0.28 & 0.25 & 0.09 & 0.03 & 0.02 & 0.00 \\
Contributions & 58.77 & 15.52 & 8.79 & 7.55 & 3.32 & 2.56 & 2.24 & 0.82 & 0.27 & 0.14 & 0.03 \\
Accumulated contributions & 58.77 & 74.29 & 83.08 & 90.62 & 93.94 & 96.50 & 98.74 & 99.56 & 99.83 & 99.97 & 100.00 \\
\hline
\end{tabular}

TABLE 4: Rotated component matrix.

\begin{tabular}{ccccccccccccc}
\hline & $\mathrm{a}$ & $\mathrm{b}$ & $\mathrm{c}$ & $\mathrm{d}$ & $\mathrm{e}$ & $\mathrm{f}$ & $\mathrm{g}$ & $\mathrm{h}$ & $\mathrm{i}$ & $\mathrm{j}$ & $\mathrm{k}$ \\
\hline 1 & 0.00 & -0.77 & -0.28 & 0.95 & 0.94 & 0.91 & -0.20 & -0.32 & 0.42 & 0.81 & 0.48 \\
2 & 0.25 & 0.27 & -0.08 & 0.16 & 0.21 & 0.21 & 0.02 & -0.87 & 0.82 & 0.21 & 0.84 \\
3 & 0.93 & 0.09 & -0.27 & -0.02 & 0.03 & 0.05 & 0.88 & -0.19 & 0.25 & 0.19 & 0.16 \\
4 & 0.16 & -0.18 & -0.91 & 0.11 & 0.16 & 0.21 & -0.13 & -0.09 & 0.34 & 0.21 & 0.22 \\
\hline
\end{tabular}

a: Longitude; b: Latitude; c: Evaluation; d: $T_{\max }$; e: $T_{\text {mean }}$; f: $T_{\min }$; g: Wind speed; h: Sunshine hour; i: Humidity; j: Vapor pressure; k: Precipitation.

has bigger loading on $T_{\max }, T_{\text {mean }}, T_{\min }$, and vapor pressure and the loading value reduces in turn, of which the temperature variables loading values are more than 0.9. Vapor pressure, latitude, and temperature can be considered as thermodynamic factors and they are the most critical factors influencing aridity index. Humidity, sunshine hour, and precipitation have bigger absolute value of load on the second principal component. Humidity and precipitation belong to the moisture factor and have positive relationship with the second principal component. Sunshine hour belongs to the radiation factor. Longitudes and wind speed which belong to the geographical, dynamic factor, respectively, have big absolute value of load on the third principal component. Absolute value of evaluation load is the biggest in the fourth principal component and it belongs to geographical factor.

\section{Conclusions}

Using the Penman formulation of $\mathrm{ET}_{0}$, precipitation, and other geographical variables during 1960-2013 in China, authors analyze the spatial and temporal variation of the aridity index and explore its influencing factors (i.e., four principal components). The following conclusions are drawn from this research.

(1) Spatial distribution of aridity index: arid region locates in mainly NWRB, a little part of northwest in YeRB and northwest of SWRB. The semiarid region includes most part of SRB, LRB, YeRB, and SWRB, whole part of HaRB, and half of HuRB in the north part. Semihumid region consists of east SRB, LRB, south of HuRB, north of YaRB, east of SWRB, and west of PRB. Humid region includes most of YaRB, PRB, and all of SERB. Scope of arid region is the minimum in summer and maximum in winter.

(2) Temporal change of aridity index: annual average of aridity index is between 3.4 and 7.5; the driest year appeared in 1980 and the wettest year appeared in 2003 and it shows decrease trend with a tendency of -0.236 per decade at $99 \%$ confidence level. In NWRB, HaRB, HuRB, LRB, NWRB, SRB, and whole China, July is the wettest month, in PRB, SERB, and YaRB, June is the wettest month, and in YeRB, September is the wettest month. The driest month dispersed in January, March, April, October, and December.

(3) Spatial and periodic characteristics of interannual aridity index contour line: the average coordinate for aridity index contour lines of $1,1.5$, and 4 is $(115.1,35.24)$, (113.35, $37.91)$, and $(95.87,32.74)$. Mean center point of aridity index contour line moves towards the south and the west during 1960-2013. In both longitudinal and latitudinal direction, there exist 10-year and 25-year cycles in shift for aridity index 1 contour coordinate, 6-year and 26-year cycles in shift for aridity index 1.5 contour coordinate, and 5-year and 25-year cycles in shift for aridity index 1.5 contour coordinate.

(4) Principal components influencing aridity index: there are 4 principal components which influence the change of aridity index. $T_{\text {mean }}, T_{\max }, T_{\min }$, vapor pressure, and latitude comprise the first component and they all can be considered as thermodynamic factors. Humidity, precipitation, and sunshine hour consist of the second principal component and they belong to the moisture factor and radiation factor. Longitudes and wind speed which belong to the geographical, dynamic factor, respectively, are the third principal component. Evaluation which belongs to geographical factor consists of the fourth principal component.

\section{Conflict of Interests}

The authors declare that there is no conflict of interests regarding the publication of this paper.

\section{Acknowledgments}

This study was supported by the National Natural Science Foundation of China (Grant no. 51279063), the Program for the New Century Excellent Talents in University (Grant no. NCET-13-0794), the Key Projects in the National Science \& Technology Pillar Program during the Twelfth Five-year Plan Period (Grant no. 2012BAC19B00), the Plan for Scientific Innovation Talent of Henan Province in China (Grant no. 144100510014), and the Support Plan of the Education Department of Henan Province for Science and Technology Innovation Teams (Grant no. 15IRTSTHN030). 


\section{References}

[1] UNESCO, Map of the World Distribution of Arid Regions: Map at Scale 1:25,000,000 with Explanatory Note, United Nations Educational, Scientific and Cultural Organization, Paris, France, 1969.

[2] Food and Agriculture Organization, "Arid zone forestry: a guide for field technicians," in FAO Conservation Guide, J. P. Lanly, Ed., FAO, Rome, Itlay, 1989.

[3] United Nations Environment Programme (UNEP), World Atlas of Desertification, Edward Arnold, London, UK, 1992.

[4] V. M. Ponce, R. P. Pandey, and S. Ercan, "Characterization of drought across climatic spectrum," Journal of Hydrologic Engineering, vol. 5, no. 2, pp. 222-224, 2000.

[5] J.-Y. Zheng, Y.-H. Yin, and B.-Y. Li, "A new scheme for climate regionalization in China," Acta Geographicasinica, vol. 6, no. 1, pp. 3-11, 2010.

[6] J.-Y. Zheng, J.-J. Bian, Q.-S. Ge, and Y.-H. Yin, "The climate regionalization in China for 1951-1980 and 1981-2010," Geographical Research, vol. 32, no. 6, pp. 988-997, 2013.

[7] H. L. Penman, "Natural evaporation from open water, bare soil and grass," Proceedings of the Royal Society of London, Series A: Mathematical and Physical Sciences, vol. 193, pp. 120-145, 1948.

[8] Q. Zhang, C.-Y. Xu, and Z.-X. Zhang, "Observed changes of drought/wetness episodes in the Pearl River basin, China, using the standardized precipitation index and aridity index," Theoretical and Applied Climatology, vol. 98, no. 1-2, pp. 89-99, 2009.

[9] Z. Yuan, D.-H. Yan, Z.-Y. Yang, J. Yin, and Y. Yuan, "Research on temporal and spatial change of $400 \mathrm{~mm}$ and $800 \mathrm{~mm}$ rainfall contours of China in 1961-2000," Advances in Water Science, vol. 25, no. 4, pp. 494-502, 2014.

[10] X.-M. Liu, D. Zhang, Y.-Z. Luo, and C.-M. Liu, "Spatial and temporal changes in aridity index in northwest China: 1960 to 2010," Theoretical and Applied Climatology, vol. 112, no. 1-2, pp. 307-316, 2013.

[11] M. Türkeş, "Spatial and temporal variations in precipitation and aridity index series of Turkey," in Mediterranean Climate: Variability and Trends, H.-J. Bölle, Ed., Regional Climate Studies, chapter 5, pp. 181-213, Springer, Berlin, Germany, 2003.

[12] H. Tabari and M.-B. Aghajanloo, “Temporal pattern of aridity index in Iran with considering precipitation and evapotranspiration trends," International Journal of Climatology, vol. 33, no. 2, pp. 396-409, 2013.

[13] P. T. Nastos, N. Politi, and J. Kapsomenakis, "Spatial and temporal variability of the aridity index in Greece," Atmospheric Research, vol. 119, pp. 140-152, 2013.

[14] H.-P. Huang, Y.-P. Han, M.-M. Cao, J.-X. Song, H. Xiao, and W.L. Cheng, "Spatiotemporal characteristics of evapotranspiration paradox and impact factors in China in the period of 19602013," Advances in Meteorology, vol. 2015, Article ID 519207, 10 pages, 2015.

[15] R. G. Allen, L. S. Pereira, D. Raes, and M. Smith, "Crop evapotranspiration guidelines for computing crop water requirements," FAO Irrigation and Drainage Paper 56, Food and Agriculture Organization of the United Nations, Rome, Italy, 1998.

[16] J. A. Hevesi, J. D. Istok, and A. L. Flint, "Precipitation estimation in mountainous terrain using multivariate geostatistics. Part I: structural analysis," Journal of Applied Meteorology, vol. 31, no. 7, pp. 661-676, 1992.
[17] J. A. Hevesi, A. L. Flint, and J. D. Istok, "Precipitation estimation in mountainous terrain using multivariate geostatistics. Part II: isohyetal maps," Journal of Applied Meteorology, vol. 31, no. 7, pp. 677-688, 1992.

[18] H. Wang, D.-H. Yan, D.-Y. Qin, and J.-H. Wang, "A study of the spatial shift of $400 \mathrm{~mm}$ rainfall contours in the Yellow River Basin during recent 50 years," Advances in Earth Science, vol. 20, no. 6, pp. 649-655, 2005.

[19] W.-Q. Xing, W.-G. Wang, Q.-X. Shao, S.-Z. Peng, Z.-B. Yu, and J. Taylor, "Changes of reference evapotranspiration in the Haihe River Basin: present observations and future projection from climatic variables through multi-model ensemble," Global and Planetary Change, vol. 115, pp. 1-15, 2014.

[20] H. B. Mann, "Non-parametric tests against trend," Econometrica, vol. 13, pp. 245-259, 1945.

[21] M. G. Kendall, Rank Correlation Measures, Charles Griffin, London, UK, 1975.

[22] Y. Dinpashoh, D. Jhajharia, A. Fakheri-Fard, V. P. Singh, and E. Kahya, "Trends in reference crop evapotranspiration over Iran," Journal of Hydrology, vol. 399, no. 3-4, pp. 422-433, 2011.

[23] J.-L. Fu, W.-H. Qian, and X. Lin, "Trends in graded precipitation in China from 1961 to 2000," Advances in Atmospheric Sciences, vol. 25, no. 2, pp. 267-278, 2008. 

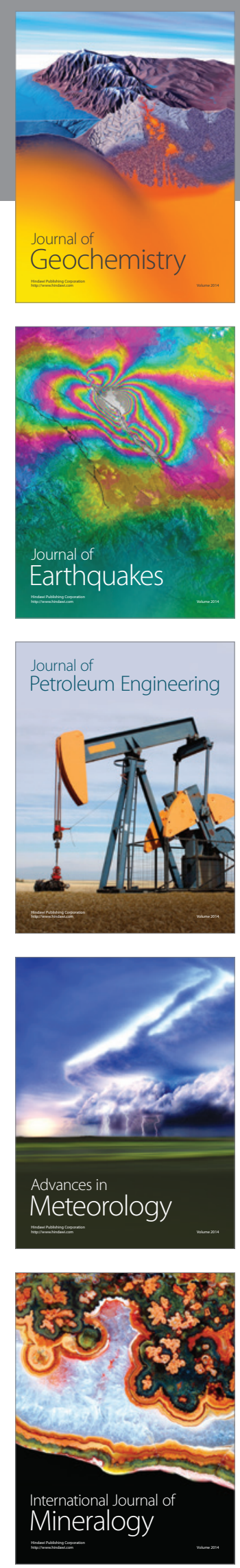
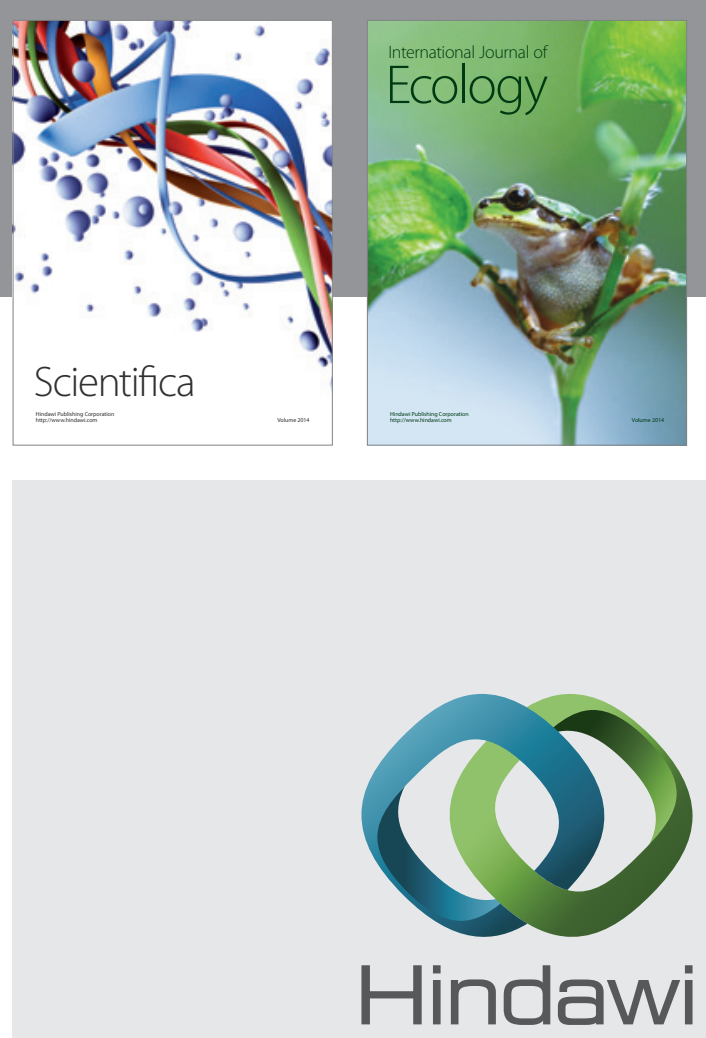

Submit your manuscripts at

http://www.hindawi.com
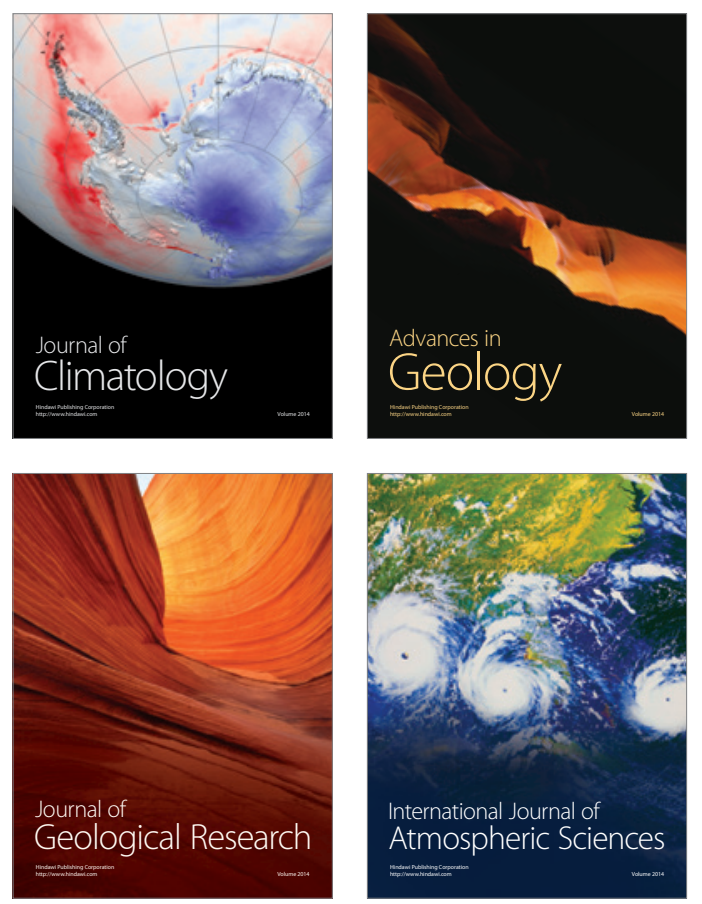

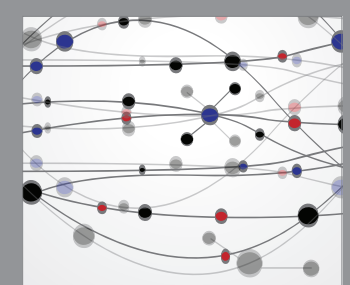

The Scientific

\section{World Journal}
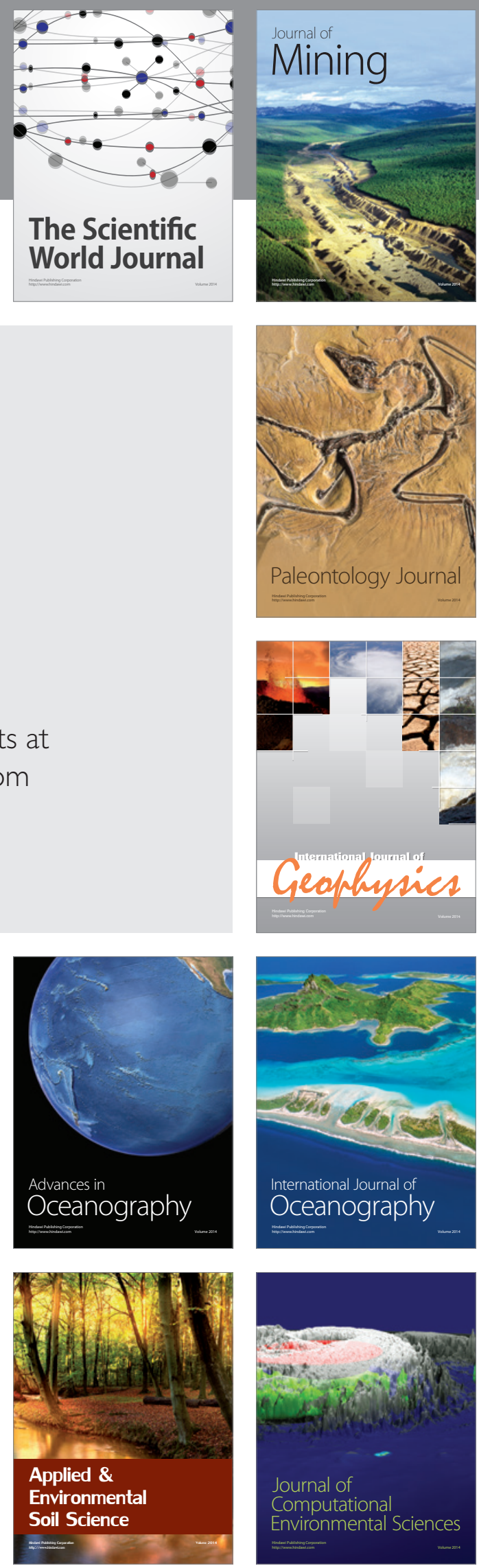